\title{
O uso das peças teatrais na análise sócio-histórica do português brasileiro
}

\author{
Milena Aparecida de ALMEIDA (D) \\ Universidade Estadual Paulista (UNESP) \\ Leticia Gaspar PINTO @ \\ Universidade Estadual Paulista (UNESP)
}

RESUMO

OPEN ACCESS

EDITADO POR

Raquel Freitag

REVISADO POR

Huda da Silva Santiago

SOBRE OS AUTORES

Milena Aparecida de Almeida Contribuiu com Leticia Gaspar Pinto. Papéis: escrita - rascunho original.

Leticia Gaspar Pinto Contribuiu com Milena Aparecida de Almeida. Papéis: escrita - análise e edição.

DATAS

Recebido: 25/07/2020 Aceito: $08 / 10 / 2020$

Publicado: 19/10/2020

COMO CITAR

Almeida, M. A.; Pinto, L. G (2020).

O uso das peças teatrais na

análise sócio-histórica do

português brasileiro. Revista da

Abralin, v. 19, n. 2, p. 1-5, 2020.

Nesta mesa-redonda, foram discutidos, a partir dos pressupostos teóricos da Sociolinguística Histórica, os desafios encontrados pelos pesquisadores dessa área de estudo. Um desses desafios refere-se aos materiais utilizados como fonte de análise, uma vez que eles são predominantemente escritos e fragmentados. A fim de solucionar esses entraves, as debatedoras apontaram caminhos diversos, como a utilização de determinados gêneros textuais para a realização das investigações históricas. Nesta resenha, demos um maior enfoque à proposta de uso das peças teatrais e em como elas podem ser uma solução aos desafios da Sociolinguística Histórica. Dessa forma, nossa discussão irá se pautar, principalmente, em três questões apontadas por Berlinck: (i) a natureza dos textos que se pode considerar na pesquisa; (ii) as formas de compreender o contexto sócio-histórico da produção desses textos e (iii) as diferenças que podem resultar do estudo de fenômenos linguísticos em textos de naturezas distintas.

\section{ABSTRACT}

In this roundtable, from the theoretical assumptions of Historical Sociolinguistics, the challenges encountered by researchers in this study area were discussed. One of these challenges refers to the materials used as a source of analysis, since they are predominantly written and fragmented. In order to solve these obstacles, the debaters pointed out different paths, such as the use of certain textual genres to carry out historical investigations. In this review, we gave a greater focus to the proposal to use plays 


\section{REVISTA DA ABRALIN}

and how they can be a solution to the challenges of Historical Sociolinguistics. Thus, our discussion will be based mainly on three issues raised by Berlinck: (i) the nature of the texts that can be considered in the research; (ii) the ways of understanding the socio-historical context of the production of these texts and (iii) the differences that may result from the study of linguistic phenomena in texts of different natures.

PALAVRAS-CHAVE

Sociolinguística Histórica. Desafios. Peças teatrais.

\section{KEYWORDS}

Socio-Historical Linguistics. Challenges. Plays.

Estudar a história de uma língua não é uma tarefa fácil. Um dos primeiros obstáculos que o pesquisador interessado em linguística histórica enfrentará é a construção e a organização do corpus, visto que o único material possível de análise é o escrito e ele se encontra, muitas vezes, limitado e fragmentado. Outro obstáculo se associa ao tratamento e quantificação dos fenômenos linguísticos, que serão alvos de análise. No entanto, ao longo dos anos, pesquisadores de diferentes vertentes teóricas, com especial destaque aos sociolinguistas, vêm apresentando caminhos possíveis para superação de alguns dos entraves.

Nessa perspectiva, as professoras doutoras Rosane de Andrade Berlinck (UNESP/CNPq), Célia Regina dos Santos Lopes (UFRJ/CNPq) e Huda da Silva Santiago (UEFS) discutem esses aspectos na mesa-redonda intitulada Sociolinguística Histórica no Brasil: caminhos e desafios. A transmissão ao vivo se deu pelo canal da Associação Brasileiro de Linguística (ABRALIN) no Youtube e foi realizada em 18 de julho de 2020 às 17h, com duração de 1 h e 50 minutos.

Ao longo dessa mesa-redonda, as participantes, além de apresentarem os inúmeros desafios que os pesquisadores da Sociolinguística Histórica enfrentam, também apontaram diversos caminhos que podem auxiliá-los. Lopes sugere utilizar as cartas como material de análise, pois é um gênero textual mais íntimo que pode favorecer a presença de uma linguagem mais espontânea; Berlinck discute como as peças teatrais podem ser um gênero textual também muito produtivo para fazer com que emerja o vernáculo; e Santiago reflete sobre a identificação da inabilidade na escrita em corpora diacrônicos.

Nesta resenha, atentar-se-á sobre a discussão realizada pela professora Rosane Berlinck, a qual apresenta alguns caminhos profícuos para a investigação da história da língua. A pesquisadora divide sua fala em três momentos, o (i) em que discutirá a natureza dos textos que se pode considerar na pesquisa; (ii) as formas de compreender o contexto sócio-histórico da produção desses textos; e (iii) as diferenças que podem resultar do estudo de fenômenos linguísticos em textos de naturezas distintas. 


\section{REVISTA DA ABRALIN}

No que se refere à primeira parte, tomamos uma afirmação relevante para a discussão: "a arte de fazer bom uso de dados ruins" (LABOV, 1994, p. 11, tradução nossa'). Labov estava, em poucas palavras, descrevendo a Linguística Histórica, porém a assertiva também é bem-vinda no contexto da Sociolinguística Histórica, afinal ao construir o corpus de análise, o pesquisador encontra um material escrito que foi conservado ao acaso pelo tempo - sem qualquer justificativa do porquê um ou outro ter "sobrevivido". Além disso, como foi apontado por Lopes, esses materiais não represen$\operatorname{tam}^{2}$ a sociedade como um todo, visto que apenas uma parcela restrita da população era alfabetizada. Outro desafio é que eles, por serem escritos, estão muito associados à norma culta, o que pode dificultar o aparecimento de uma fala mais espontânea.

Berlinck defende a relevância de adotar o gênero dramático (como as peças de teatro) para a investigação da mudança linguística, uma vez que elas são construídas através do diálogo, o que, de alguma forma, pode aproximar do vernáculo do período. Essa questão pode ser vista, principalmente, na comédia que apresenta um tom jocoso e busca reproduzir uma fala menos formal, que caracterize os personagens em cena segundo suas posições sociais e características físicas e psicológicas.

Ainda sobre as peças, Berlinck nos convida a refletir sobre os elementos constitutivos do gênero dramático, como a construção composicional, o conteúdo temático e o estilo verbal. Segundo a pesquisadora, compreender os elementos composicionais é um dos aspectos que auxiliam no entendimento do plano de fundo da fala em uso, o que reforçaria e traria mais fidedignidade às análises realizadas pelo pesquisador da sociolinguística histórica. Berlinck também destaca, brilhantemente, a relevância de olhar as rubricas e o locus em que as cenas são construídas, pois servem de apoio para a compreensão dos fatos sócio-históricos.

No que diz respeito à segunda parte da apresentação, Berlinck apresenta estratégias que podem ser utilizadas para se captar o contexto sócio-histórico a partir das produções recolhidas na diacronia. Um exemplo destacado por ela é a importância de averiguar os papéis sociais dos períodos estudados, uma vez que uma transposição da faixa etária do indivíduo ou de sua classe social atual para o passado pode causar um grande problema, posto que ser jovem no século XXI não equivale ou se equipara a ser jovem no século XIX, por exemplo.

Esse caminho de adoção das peças de teatro como material de análise e o cuidado de perfilar os papéis sociais já é adotado, tal como mostrou a pesquisadora, pelo grupo de pesquisa que ela coordena, o Núcleo de Pesquisas em Sociolinguística de Araraquara (SoLAr). Berlinck não dá muitos detalhes sobre o projeto em andamento, dada a limitação do tempo de apresentação, mas esclarece que o SoLAr tem se dedicado a organizar e construir um corpus com peças de teatro do século XIX, XX e XXI e, para além disso, se debruçar sobre os papéis sociais dos personagens das peças.

1 No original: "the art of making the best use of bad data" (LABOV, 1994, p. 11).

2 Destacamos que noções de representatividade são problematizadas e discutidas de modos diferentes a depender da perspectiva adotada. Nesta resenha, nos referimos exclusivamente ao modo como a Sociolinguística Varicionista busca diferentes perfis sociais para investigações das formas linguísticas. 


\section{REVISTA DA ABRALIN}

A produtividade do projeto se verifica no estudo diacrônico da realização do objeto direto anafórico em comédias brasileiras do século XIX de Cyrino (1993). Um dos materiais utilizados pela pesquisadora, a peça O Demônio Familiar de José Alencar, apresenta os casos de objeto direto realizado por meio de um pronome tônico na fala de um único personagem, Pedro. Ele é retratado como um jovem negro, escravo e responsável pelas peripécias e intrigas do enredo. Nesse sentido, retomando um trabalho anterior de Berlinck, Barbosa e Marine (2008, p. 188), podemos apontar que

\footnotetext{
esse personagem é caracterizado como interesseiro, malandro; sua linguagem se aproxima muito da expressão infantil. O fato de os dados de pronome tônico na função de objeto direto estarem concentrados apenas em sua fala não nos parece fortuito. Esse emprego agrega à forma certos valores, sugerindo que é própria de uma variedade popular (e inculta). Assim, o uso feito pelo autor revela mais sobre uma norma subjetiva (aquilo que se acha correto e prestigioso) que sobre a norma objetiva, vigente no momento histórico analisado
}

Fundamentada nos resultados de Cyrino (1993), a caracterização dos personagens possibilita investigar fenômenos linguísticos e seus significados sociais associados à construção feita pelo autor de determinados personagens. Tal movimento é possível, pois amplia o escopo do estudo ao refletir sobre os representantes do possível estigma, localizando-os dentro de um determinado contexto de variedade popular.

Por fim, a terceira questão diz respeito às diferenças que resultam da análise de fenômenos linguísticos em textos de natureza diferente. A problematização se faz no sentido de que não é o ideal tomar apenas um gênero como representativo de uma determinada sincronia dentro da his tória de uma língua, seja ela presente ou passada.

A proposta apresentada parte da abordagem comparativa entre gêneros de Romaine (1985), pensando em dois caminhos: (i) em estudos sincrônicos, o que permite analisar o movimento das formas linguísticas em variação dentro de um continuum estilístico; (ii) em estudos diacrônicos, o que permite observar a história de uma língua através da história dos textos. Tarallo (1983), por exemplo, se coloca em conformidade com tal abordagem para dar conta de seu projeto sobre as estratégias de relativização.

Nesse sentido, o pesquisador adotou, em uma perspectiva sincrônica, dados provenientes de entrevistas sociolinguísticas, documentários, entrevistas e novelas para ter acesso a uma representatividade maior da língua dentro de diferentes gêneros - principalmente do seu significado social relacionado com a estratégia copiadora, considerada um uso estigmatizado. Em uma perspectiva diacrônica, foram utilizadas, além das peças, cartas e diários, o que permitiu um material muito mais representativo dos períodos e que foi responsável por uma melhor apreensão do fenômeno, visto que alguns períodos carecem mais de registro do que outros.

Em suma, a partir das discussões apresentadas, compreende-se que o pesquisador tem a sua disposição caminhos que podem diminuir os desafios de um estudo sócio-histórico. Desse modo, nosso foco seguiu a sugestão da Prof ${ }^{a}$ Rosane Berlinck, partindo da análise do texto dramático para uma investigação produtiva dos fenômenos de mudança linguística. Através dos exemplos, averiguamos que, tendo em vista a constituição plural das peças, agregadas à caracterização dos personagens e a soma da comparação entre gêneros, apresenta-se um percurso possível dentro da 


\section{REVISTA DA ABRALIN}

Sociolinguística Histórica. Por fim, vale ressaltar que a mesa-redonda como um todo ofereceu contribuições para o avanço da área, refletindo também sobre o gênero carta e inabilidade na escrita.

\section{REFERÊNCIAS}

BERLINCK, R. A.; BARBOSA, J. B; MARINE, T. C. Reflexões teórico-metodológicas sobre fontes para o estudo histórico da língua. Revista da ABRALIN, v.7, n. 1, p. 53-79, 2008. DOI: http://dx.doi.org/10.5380/rabl.v7i2.52494.

CYRINO, S. M. L. Observações sobre a mudança diacrônica no português do Brasil: objeto nulo e clíticos. In: KATO, M.; ROBERTS, I. (org.) Português brasileiro: uma viagem diacrônica. Campinas: Ed. UNICAMP, 1993, p. 163184.

LABOV, W. Principles of Linguistic Change, vol. 1: Internal Factors. Cambridge, MA/Oxford: Blackwell Publishers, 1994

ROMAINE, S. Socio-Historical Linguistics. New York: Cambridge University Press, 1985.

SOCIOLINGUÍSTICA Histórica no Brasil: caminhos e desafios. Mesa-redonda debatida por Rosane de Andrade Berlinck, Célia Regina dos Santos Lopes e Huda da Silva Santiago, sob mediação de Rosane de Andrade Berlinck, 2020. 1 vídeo (1h 49min 20s). Publicado pelo canal da Associação Brasileira de Linguística. Disponível em: https://www.youtube.com/watch?v=nE4i53QDacE\&t=4054s. Acesso em: 18 jul 2020.

TARALLO, F. L. Relativization strategies in Brazilian Portuguese. PhD Dissertation - University of Pennsylvania, Philadelphia, 1983. 